\title{
Technical Approach
}

The approach that we propose here in this SBIR proposal is a modified water electrolysis cell. In conventional water electrolysis the $\mathrm{H}_{2} \mathrm{O}$ is split into electrons, protons, and oxygen gas at the anode electrode. The electrons travel through an external power source and the protons travel through an electrolyte membrane to the cathode where they recombine to form hydrogen gas. The power source requires a minimum of $1.23 \mathrm{~V}$ to overcome the potential difference of the electrodes for the splitting of water.

In contrast in our approach proposed here, instead of splitting water we are using acetate in wastewater and bacteria to oxidize the acetate into electrons and protons at the anode surface. The microbes release the electrons to the anode and the resulting protons move to the cathode electrode through the proton exchange membrane as described above and recombine to form hydrogen gas. The advantage here is that the required potential is now on the order of 0.25 to $0.8 \mathrm{~V}$, and a considerable savings in electricity is realized to produce the same amount of hydrogen while at the same time removing organic matter from wastewater streams.

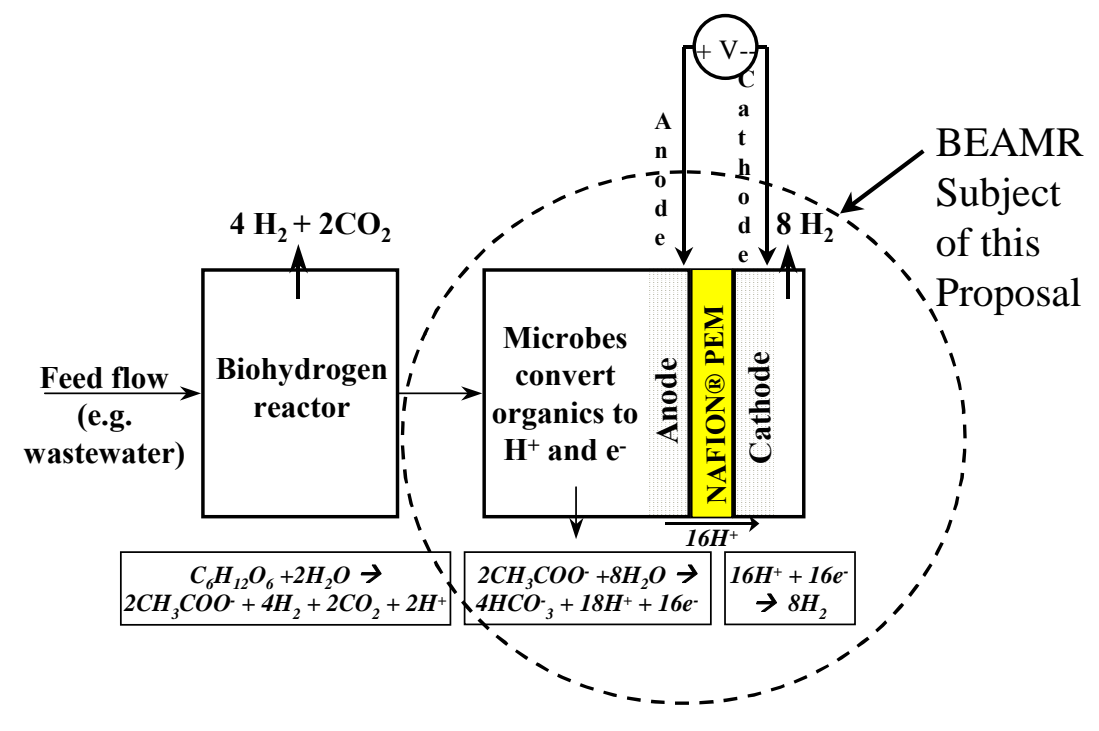

Fig. 1. The "Bio-Electrochemical Assisted Microbial Reactor" (BEAMR) is the concept of this proposal. The BEAMR will further process the effluent from a biohydrogen fermenter into up to 8 moles of hydrogen using a minimal amount of electricity.

One can consider this approach very similar to a microbial fuel cell, and in fact the anode structure and function is quite similar, however in our approach at the cathode no oxygen is supplied. This lack of oxygen makes the engineering and construction of the cell much simpler since oxygen can be excluded from the entire system. In a microbial fuel cell a significant challenge exists in the balancing the oxygen requirement of the cathode while not 
allowing too much oxygen to diffuse into the anode chamber where competing microbes can use the oxygen to digest the organic matter rather than contributing to the electron circuit.

\section{Technical Feasibility Demonstrated in Phase I}

The purpose of the Phase I research was to demonstrate in our Labs that hydrogen can be produced with a minimal voltage and that we can scale the process to the 1 cubic foot size reactor. We had identified some targets for performance in terms of efficiency. However based on reviewer comments it is apparent a target regarding size and thus costs also needs to be incorporated.

The Penn State microbial cube fuel cell was converted to perform both functions of fuel cell and with the switching of the cathode collector, and cover was introduced that allowed the cell to operate in the "BEAMR" mode and produce and collect hydrogen. See pictures below in Fig 2. The test tube is attached to a chamber that encloses the cathode electrode and allows for the volume of hydrogen to be collected and measured. The modified caps were designed and manufactured at Ion Power and supplied to Penn State for incorporation into the microbial reactors. Six of the reactors were first started in the fuel cell mode in order to grow the appropriate microbes and then the modified caps were placed on the cathodes and the cells were converted to operate in the BEAMR mode. 


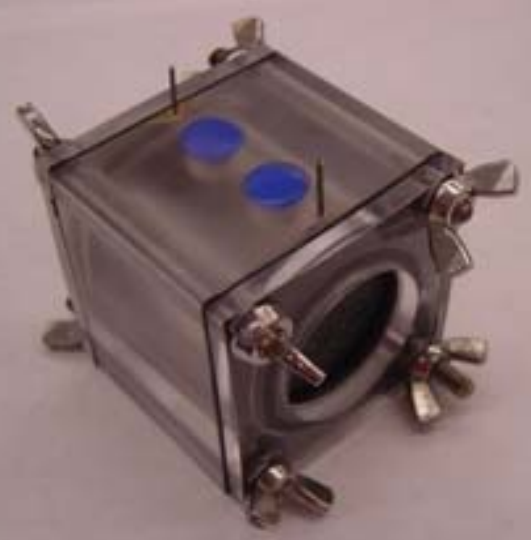

Fig 1, Picture of small microbial fuel cell with air breathing cathode at the right

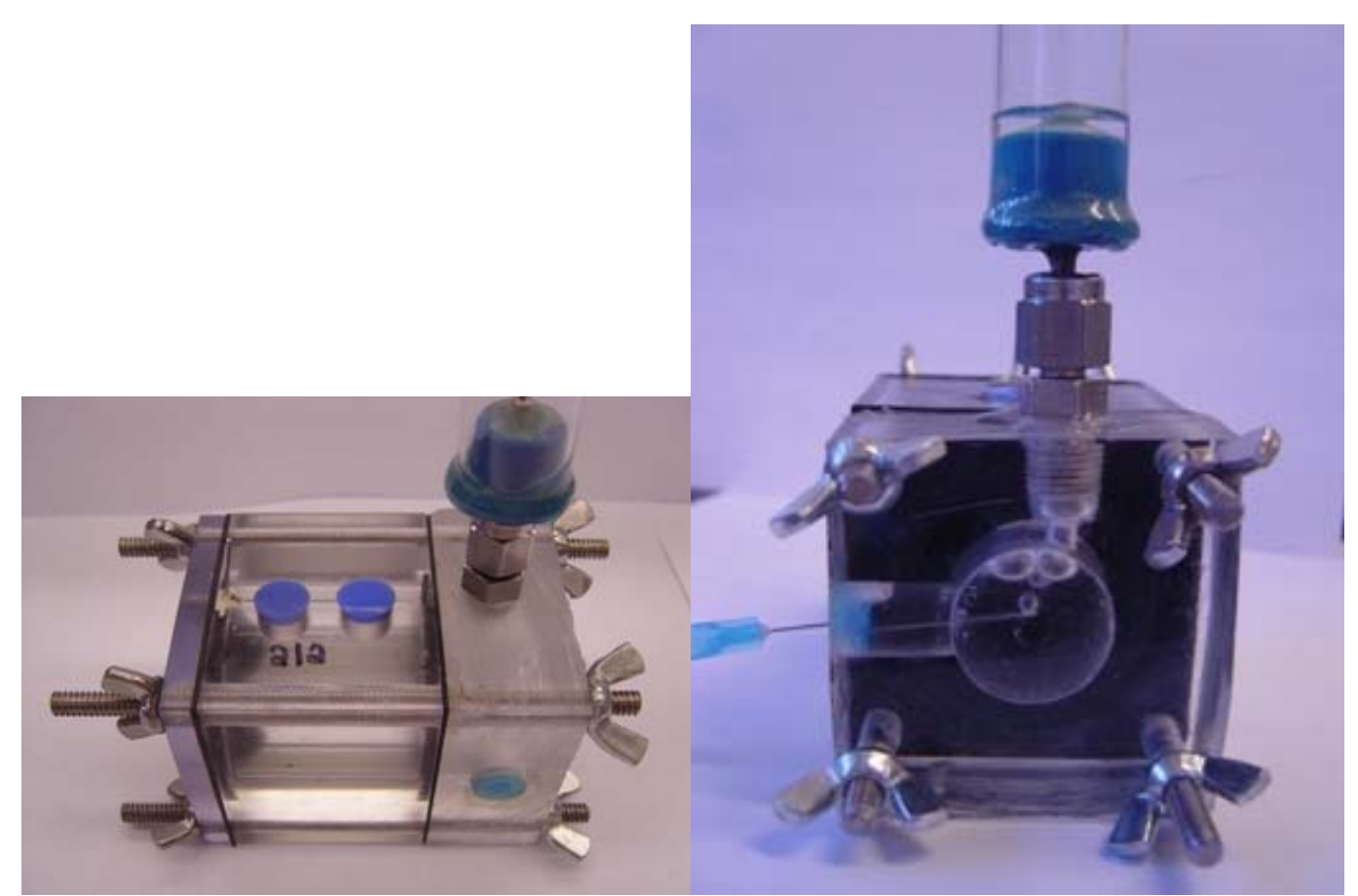

Fig 2 Modification to BEAMR with modified cathode cap to capture hydrogen produced at cathode 
We first wanted to optimize the relative performance of the BEAMR using various membrane thicknesses. We prepared catalyst coated membranes and sent them for evaluation to Penn State, one set made with the 2 mil thick NRE212 and with the 7 mil thick N117 membrane

The figure 3 below shows the measured total hydrogen as a function of operating time. One can see that the hydrogen production rate is nearly constant until a time when the organic matter in the cell is consumed.

H2 Production N117 \& N212

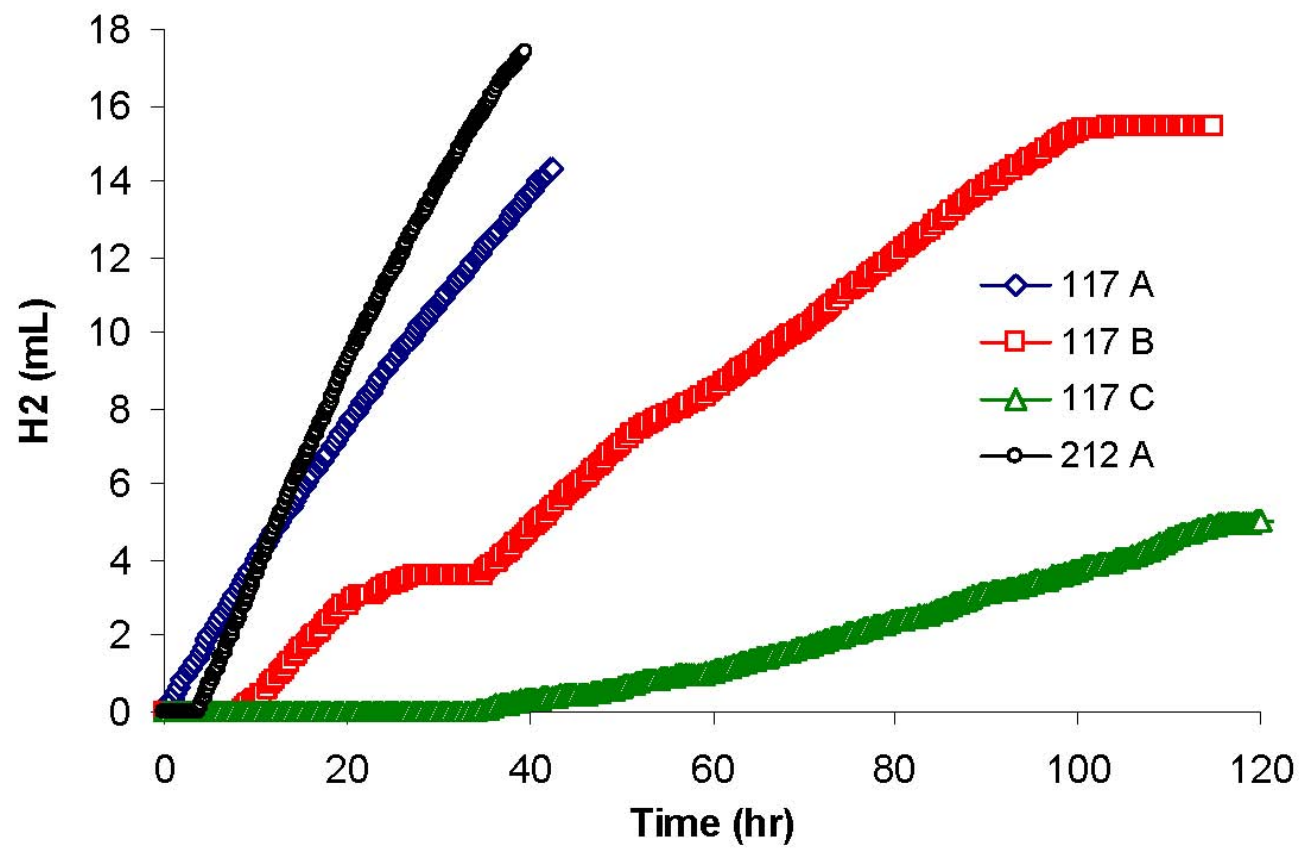

The N117A sample produced $14 \mathrm{ml}$ of Hydrogen in 40 hours. Comparing the hydrogen produced and the total current applied yields a Hydrogen Recovery of $128 \%$. Note the hydrogen recovery is defined as :

HR = Hydrogen Recovery = moles hydrogen collected $/$ moles of hydrogen electrical equivalent

For the NRE212 membrane the samples produced $18 \mathrm{ml}$ of hydrogen in 35 hours. Comparing the hydrogen produced and the total current applied to the cell a Hydrogen Recovery of $116 \%$ was achieved. Although the hydrogen recovery can not be over $100 \%$, we attribute the excess to measurement error, and concluded that the hydrogen recovery rate is not a significant limitation in our approach. 
Also the conclusion that the thinner membrane has a better performance as compared to the thicker membrane is shown in the figure above. Thus subsequent experiments were carried out on the thinner NRE 212 membrane.

At this early stage we also noticed that a significant internal resistance existed in the cell. We measured the in-plane conductivity of the Ion Power catalyst layer and found it to be excessive for collecting current in the plane of the membrane. This is not a problem in conventional fuel cells since current us collected perpendicular to the plane. To overcome this we modified our catalyst coated membrane to include a graphite gas diffusion material laminated to the surface of the cathode catalyst coating. This produced the similar current at about $1 / 2$ of the voltage, thus we were able to reduce the voltage from $1 \mathrm{~V}$ to $0.6 \mathrm{~V}$ with the same production rate, actually the production rate was even faster, $11 \mathrm{ml}$ in $20 \mathrm{hrs}$.

\section{1 \& 2 Sided MEAs @ 0.6 Volt}

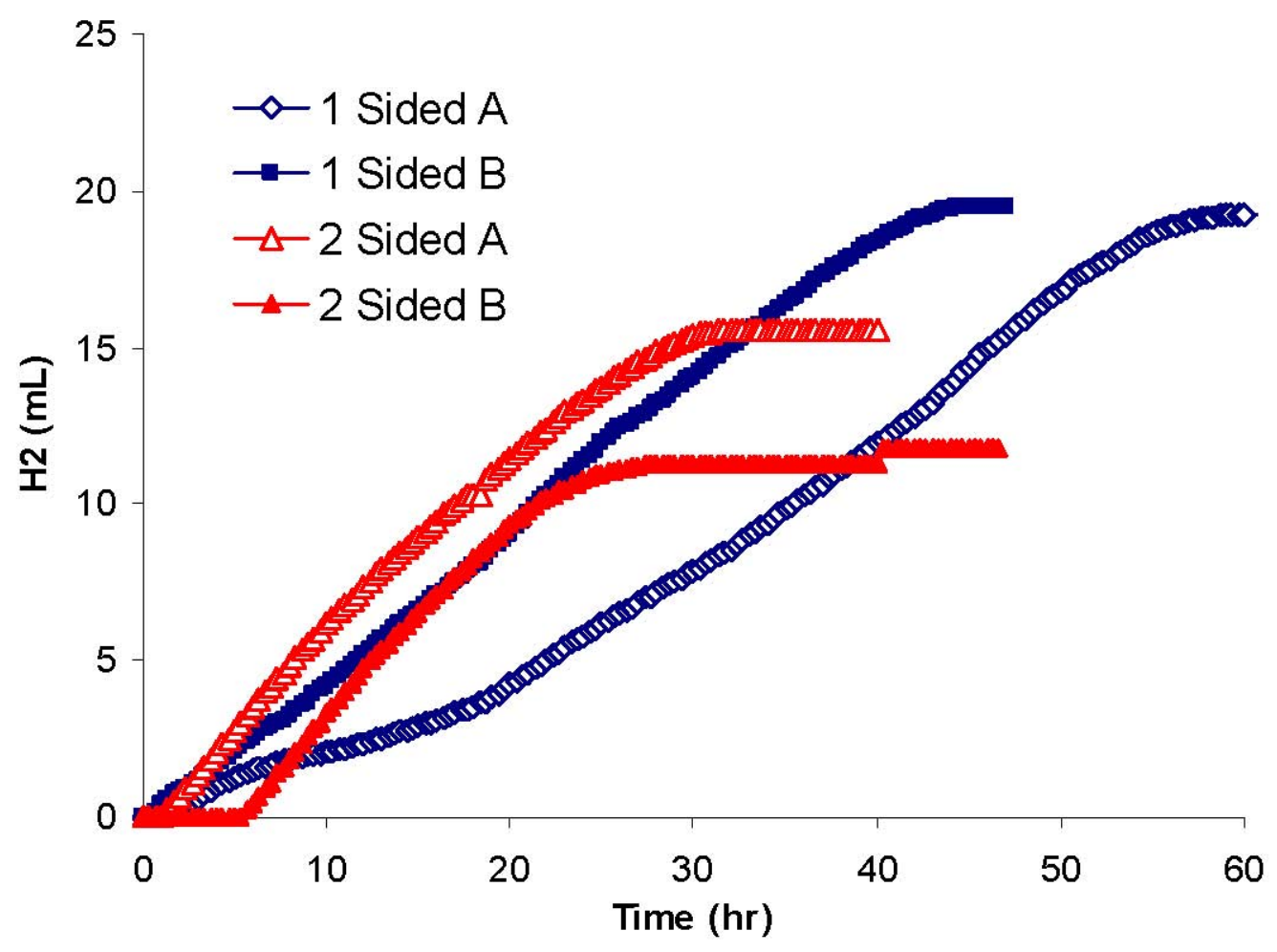

We reduced the voltage even further to $0.4 \mathrm{~V}$ and now the hydrogen production rate reduced corresponding to the reduced driving force. However we still were able to produce $8 \mathrm{ml}$ in 18 hours of operation. This represents a Hydrogen Recovery of $150 \%$. Thus we are producing more hydrogen that we are actually anticipating. We believe that the extra hydrogen that we are collecting is actually coming from the biohydrogen fermentation reaction (see left side of Fig. 1). We have seen gas formation in the anode chamber and one can easily anticipate that hydrogen can be transported electrochemically from the anode chamber to the cathode chamber via an electrochemical pumping means. That is hydrogen gas in the anode is 
disassociated into protons the protons move across the membrane and evolve again as hydrogen gas on the cathode. This reaction can occur at cell voltages of only $50 \mathrm{mV}$ and is our explanation as to why the membranes with catalyst on both faces of the membrane produce more hydrogen as seen in Fig 4 below. However assuming that we actually have $100 \%$ Hydrogen Recovery this means that our overall efficiency is 307\%; (recall our efficiency as defined in our Phase I technical targets is hydrogen recovery * $1.23 \mathrm{~V} /$ actual cell voltage)

We also scaled the reactor volume from the $25 \mathrm{ml}$ to $6800 \mathrm{ml}$ while keeping the cathode area constant. We also modified the anode structure from a small pore (10 micron) to a large pore $(1 \mathrm{~cm})$ stainless steel mesh that could occupy nearly the entire volume of the reactor. This allows for the concept of the microbial electron collection distance. We are assuming that since microbes are on the order of 1 micron, they can easily become trapped in a small pore structure anode such as a graphite diffusion media. However an open structure like a stainless steel wire mesh/sponge can engage the entire volume of the reactor. Indeed we now are obtaining much higher current densities on the same $7 \mathrm{~cm}^{2}$ cathode electrode area. In the initial start-up in fuel cell mode we measured a cell voltage of $0.95 \mathrm{~V}$ across a $1 \mathrm{k}$ Ohm

resistor. This high of a cell voltage has never been seen before in a microbial fuel cell. This tells us that in the smaller cell the cathode is not the limiting factor in the cell but rather the microbes ability to interact with the anode structure.

\section{$1 \& 2$ Sided MEAs @ 0.4 Volt}

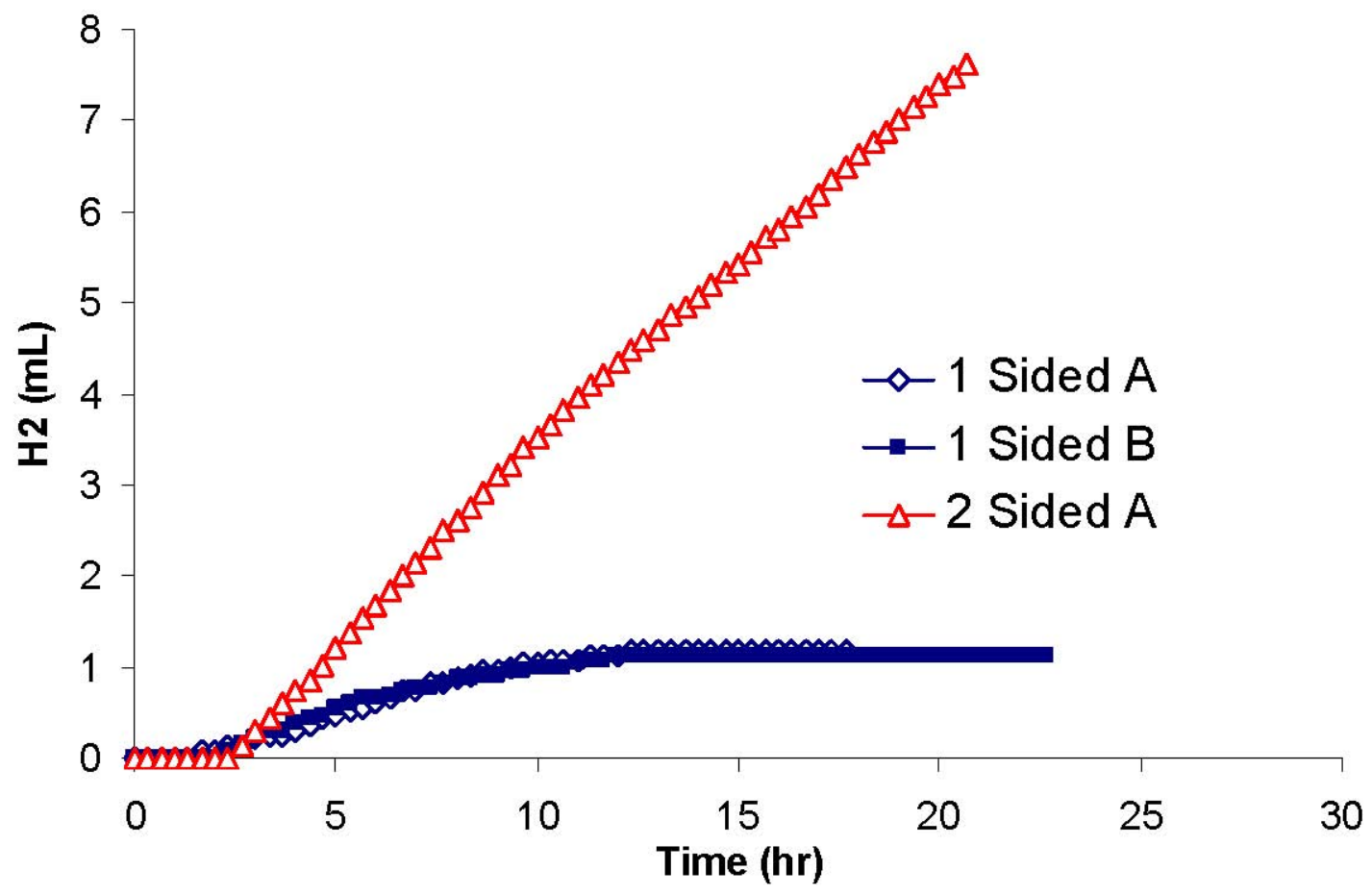


1 \& 2 Pt Sided MEAs @ 1 Volt RUN A \& B

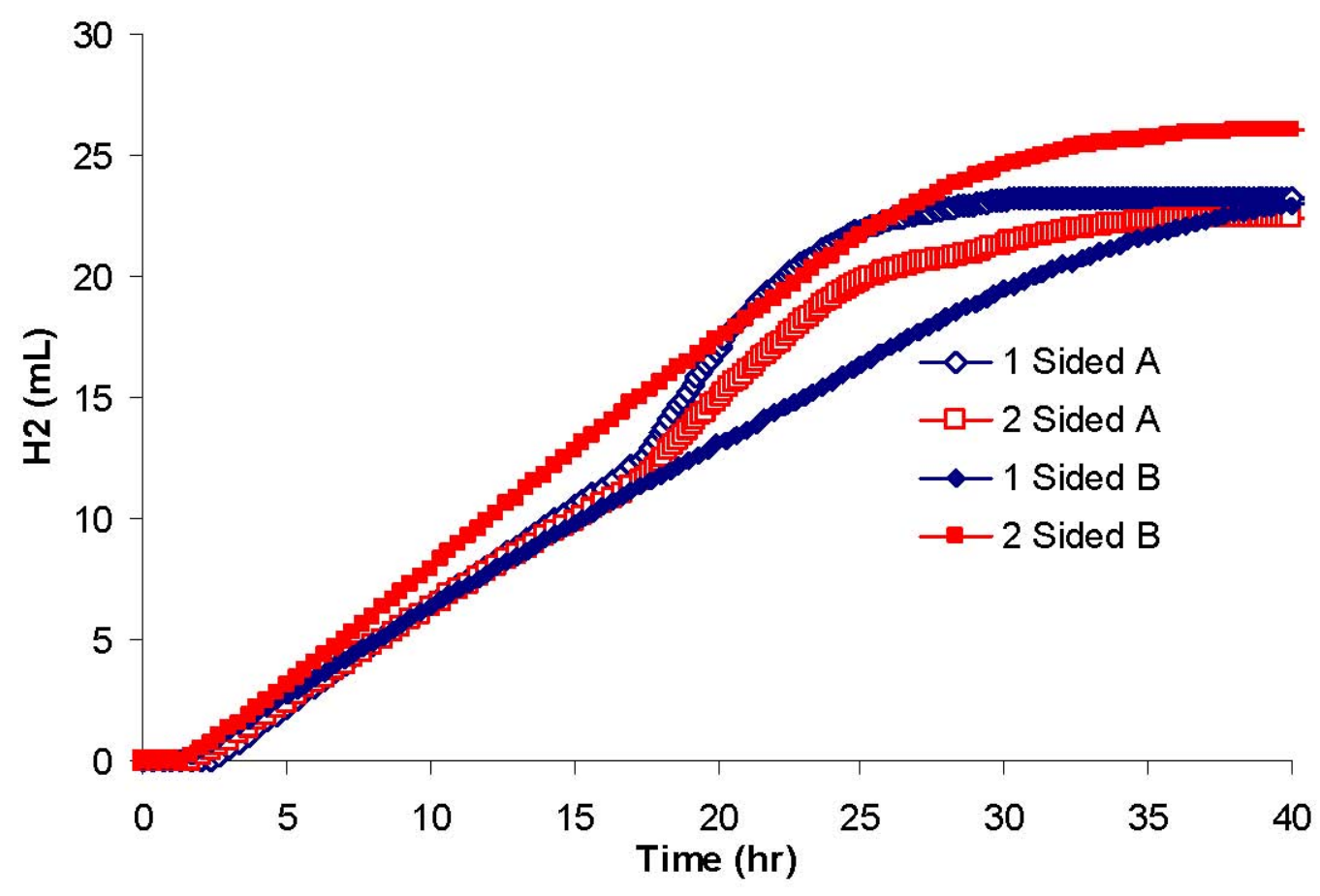

A thermodamic analysis of this data shows that hydrogen production relative to the energy content of the electricity to produce it is quite favorable. During the experiment we applied $0.17 \mathrm{~kJ}$ of electrical energy, and we produced $0.26 \mathrm{~kJ}$ of hydrogen energy, thus quite favorable. The overall efficiency when one considers the $0.3 \mathrm{~kJ}$ or Acetate consumed, yields and efficiency of hydrogen production of 56\%. The results are tabulated below for membranes with catalyst on both sides versus just one side as well as different voltages. 


$\begin{array}{cccc}\begin{array}{c}\text { Coulombic } \\ \text { Efficiency (\%) }\end{array} & \begin{array}{c}\text { Hydrogen } \\ \text { Recovery (\%) }\end{array} & \text { Yield } & \text { Efficiency } \\ 66 & 100 & 66 & \\ 70 & 87 & 61 & 1.23 \\ 71 & 76 & 54 & 1.34 \\ 44 & 47 & 21 & 1.56 \\ & & & 1.45\end{array}$

Pt Catalyst 1 side

Pt catalyst 2 sides

$\begin{array}{lllll}1.0 \mathrm{~V} & 66 & 100 & 66 & 1.23 \\ 0.8 \mathrm{~V} & 70 & 87 & 61 & 1.34 \\ 0.6 \mathrm{~V} & 71 & 76 & 54 & 1.56 \\ 0.4 \mathrm{~V} & 44 & 47 & 21 & 1.45\end{array}$

$\begin{array}{lllll}1.0 \mathrm{~V} & 79 & 87 & 69 & 1.07 \\ 0.8 \mathrm{~V} & 65 & 61 & 40 & 0.94 \\ 0.6 \mathrm{~V} & 72 & 54 & 39 & 1.11 \\ 0.4 \mathrm{~V} & 36 & 45 & 16 & 1.38\end{array}$

With these encouraging results, the Penn State team went ahead and designed and built a larger reactor, with an 10 x $10 \mathrm{~cm}$ tank size, or 1 liter volume., see picture below

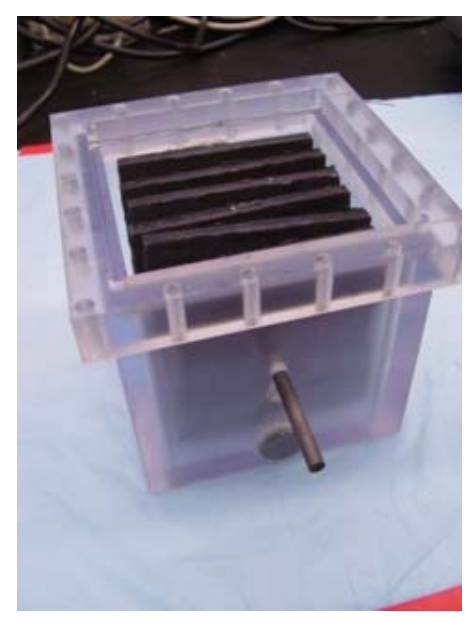


The Penn state team operated the cell in hydrogen production mode and found that the Hydrogen production rate was not that significantly better, and produced only $16 \mathrm{ml}$ of $\mathrm{H} 2$ in 10 hours of run time.

\section{BIG ONE @ 0.8 Volt}

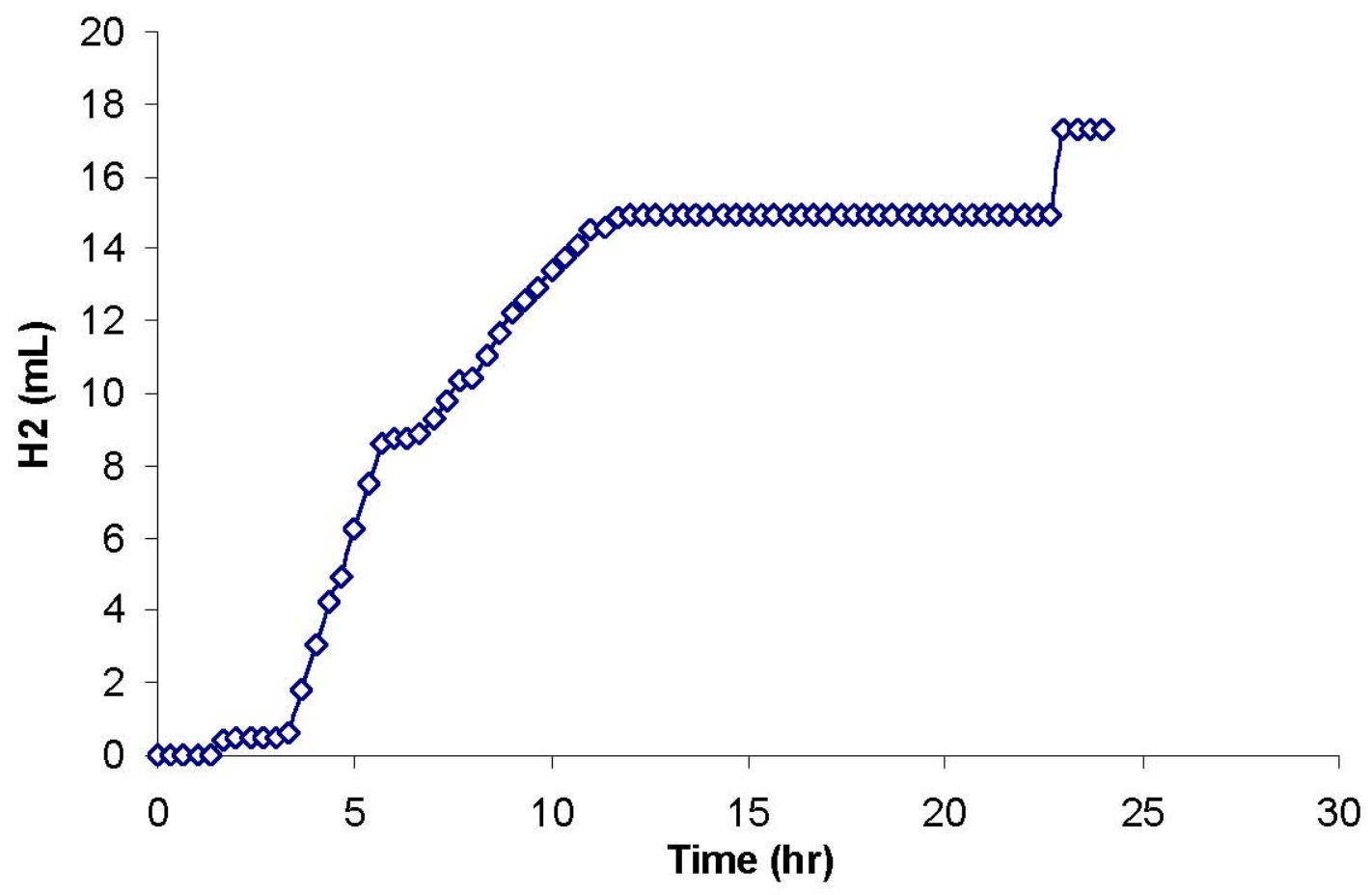

However considerably poorer performance of this reactor design is demonstrated by the thermodynamic analysis, see table below. The most dramatic was the reduced hydrogen recovery, only $0.19 \mathrm{~kJ}$ of hydrogen was recovered at the cost of $0.43 \mathrm{~kJ}$ of electricity.

\begin{tabular}{|l|l|l|l|}
\hline $\begin{array}{l}\text { Electricity } \\
\text { required }\end{array}$ & Ee & 0.43 & $\mathrm{~kJ}$ \\
\hline Substrate energy & Es & 6.9 & $\mathrm{~kJ}$ \\
\hline Hydrogen energy & Eh & 0.19 & $\mathrm{~kJ}$ \\
\hline & & & \\
\hline Overall recovery & Es,e & 2.6 & $\%$ \\
\hline $\begin{array}{l}\text { Electricity } \\
\text { Efficiency }\end{array}$ & Eee & 0.44 & $\begin{array}{l}\mathrm{kJ}-\mathrm{H} 2 \text { / kJ-electricity } \\
\text { consumed }\end{array}$ \\
\hline $\begin{array}{l}\text { Substrate } \\
\text { Efficiency }\end{array}$ & Ese & 2.07 & mol-H2 / mol-Acetate \\
\hline
\end{tabular}


At Ion Power labs we constructed a considerably larger reactor in an attempt to improve the construction design. We focused the initial testing on the fuel cell mode of operation and the optimization of the reactor. The picture of the experimental set-up is shown in the picture below. First we used a much smaller membrane 3 inch diameter as compared to the $10 \times 10$ $\mathrm{cm}$ membrane used in the Penn State reactor. We did this since we know the membrane area and cathode area is not really a limitation, but rather the anode area, so we used a stainless steel wool for a high surface area anode for good microbial interaction. During operation the approx. 1 cubic foot reactor was always switched upside down so that liquid was always in contact with the membrane and covered with a box to prevent the growth of photosynthetic bacteria. We also used a pump to provide agitation to the microbial culture and we provided a heater to have good temperature control

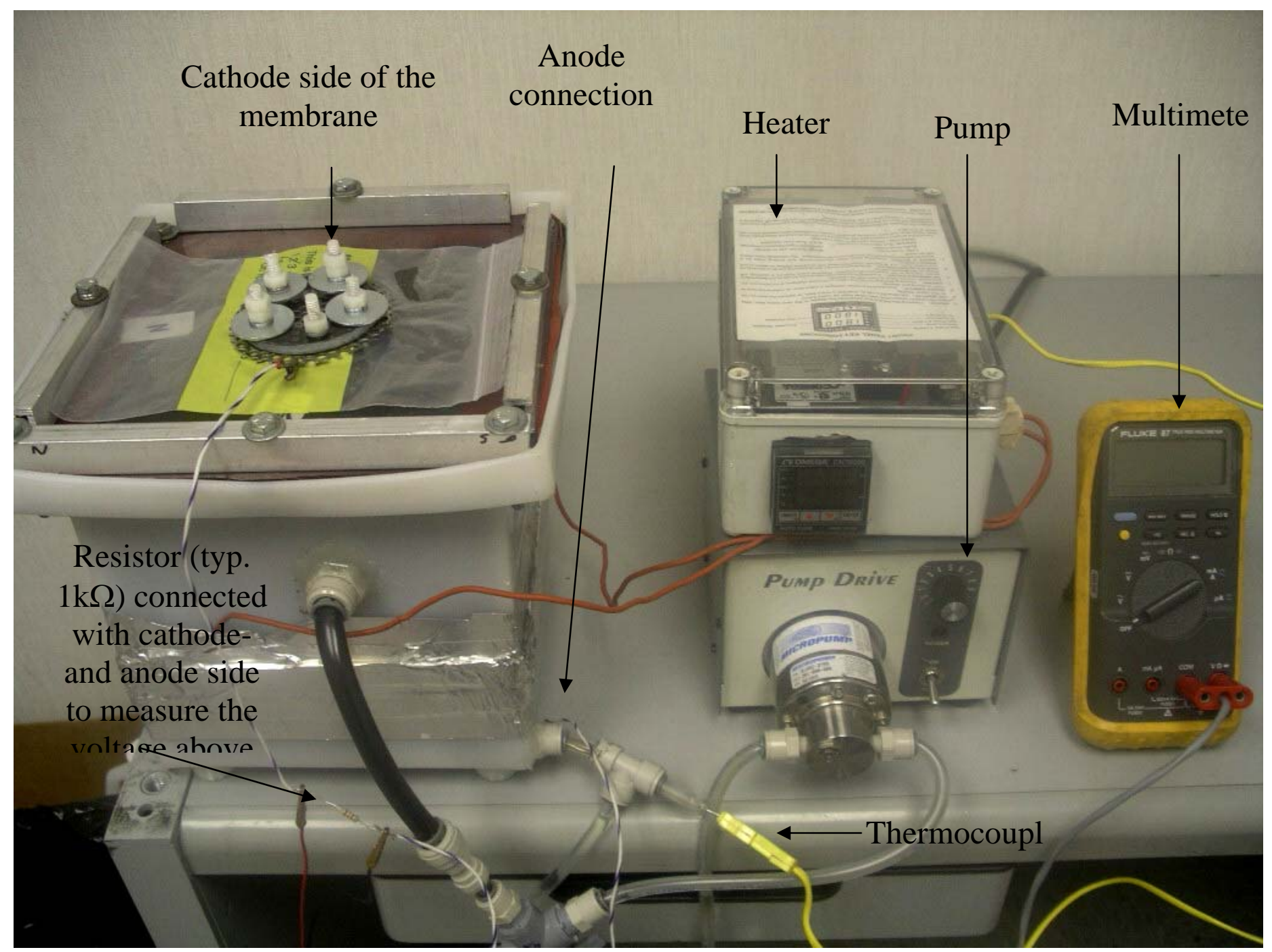

Figure 1: Experimental setup from the microbial reactor. At this picture you see the reactor (with the cathode side on top) in his "normal" position but for the experiments it was switched upside down (with the tank side on top). 
Our experimental setup consists of the following components:

Microbial Fuel Cell: $\quad$ A plastic rectangular tank with the following specifications:

Height: 8 Inches

Width: 8 Inches

Length: 8 Inches

3 inch diameter opening in "lid" for placement of catalyst coated membrane.

Capacity: 2 Gallons using locally found creek water

Heater with thermocouple: To measure and regulate the temperature inside our fuel cell.

Pump: $\quad$ To keep the water in motion inside.

Multimeter: $\quad$ To measure the voltage over a resistor, which is connected with the cathode- and anode-side from the fuel cell.

I.) First run of the reactor in fuel cell mode (measuring voltage and temperature vs. time)

For the first run the MFC was run under the following conditions:

- $1 \mathrm{~g} / \mathrm{L}$ sugar $\left(\mathrm{C}_{12} \mathrm{H}_{22} \mathrm{O}_{11}\right)$ in 2 gallons of locally found creek water

- Anode and cathode were connected with a $1 \mathrm{k} \Omega$ resistor and the voltage was measured over it

- Pump was turned on (Level 2) and the heater was turned on to $30^{\circ} \mathrm{C}$

Voltage and Temperature vs. Time @ 1000 ohms




II.) Investigation/ Influences of the internal resistance from the MFC

\section{a) Temperature vs. Resistance}

For this chart the cathode and anode were connected to the conductivity bridge and measured with $1 \mathrm{kHz}$.

Internal Resistance vs. Temperature



Results and conclusion for this investigation:

i. It's not possible to run the reactor with a high internal resistance $>200 \mathrm{ohm}$. Therefore it's necessary to determine what cell parameter influences the high internal resistance and to reduce it.

ii. The temperature has an influence on the microbial activity and therefore on the voltage that the MFC produces

\section{b) Resistance from separated parts of the MFC}

The reactor was disassembled and the separated parts were measured for resistance contribution. The separated parts and the measuring setup can be seen at the following picture. 


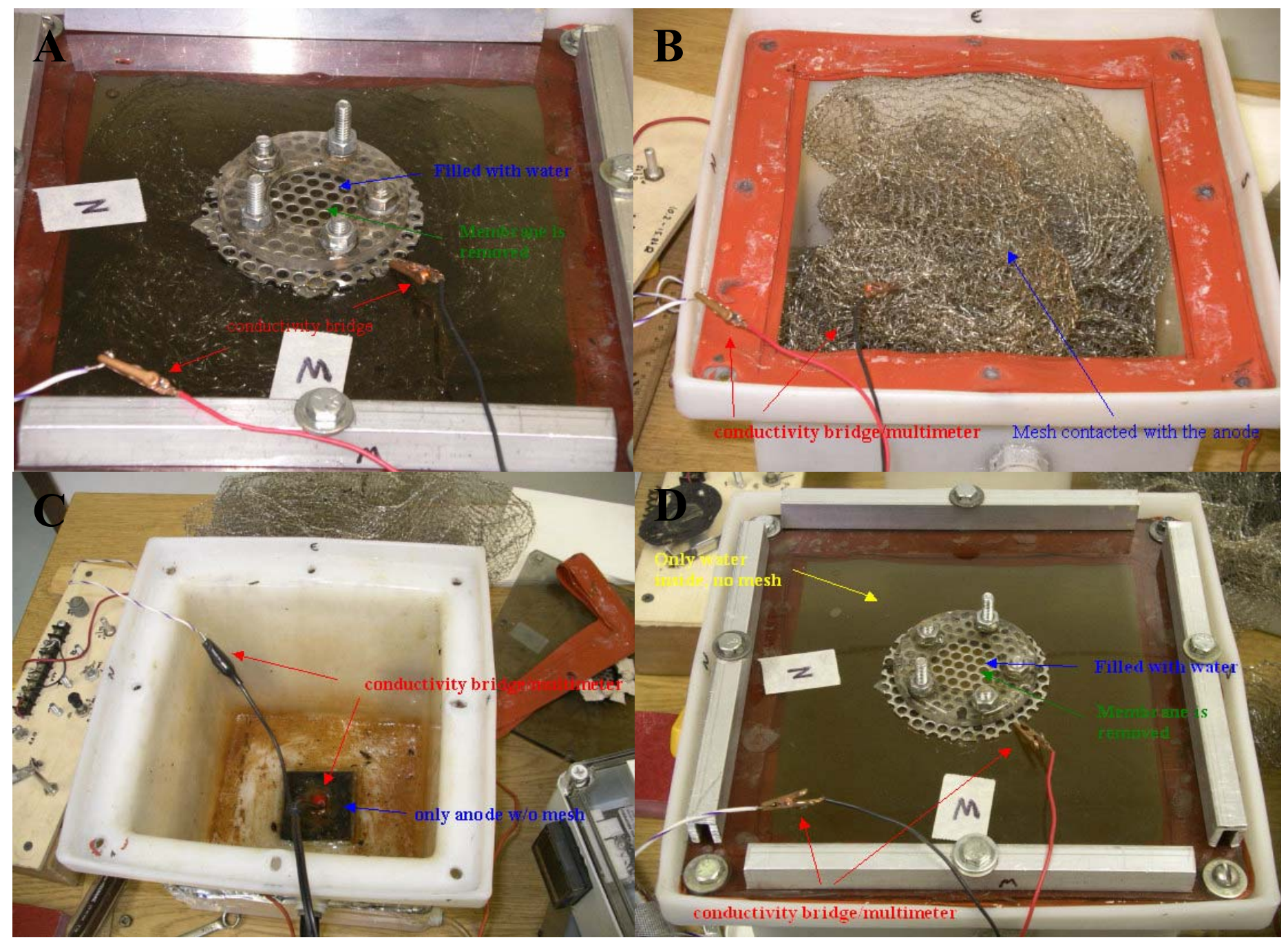

Different parts from of the inside of the reactor. (A) assembled reactor; (B) only the anode with the connected mesh; (C) only the anode without the mesh; (D) whole reactor, but without the membrane and the mesh inside to determinate the resistance from the water. 
The received results can be seen at the following Table.

Table 1: Measured results from the separated MFC

\begin{tabular}{|c|c|c|c|}
\hline Setup & Figure & $\mathbf{R} / \mathbf{\Omega}$ & Measured with \\
\hline W/o membrane & 4A & $370 @ \mathrm{~T}=28^{\circ} \mathrm{C}$ & $\begin{array}{c}\text { Conductivity bridge @ } \\
1 \mathrm{kHz}\end{array}$ \\
\hline Mesh and anode only & 4B & 5.1 & Flux 87 multimeter \\
\hline Anode only & 4C & 3.9 & Flux 87 multimeter \\
\hline Only water & 4D & $1400 @ \mathrm{~T}=27^{\circ} \mathrm{C}$ & $\begin{array}{c}\text { Conductivity bridge @ } \\
1 \mathrm{kHz}\end{array}$ \\
\hline
\end{tabular}

Results and conclusion for this investigation:

i. One important part for the high internal resistance is the conductivity from the creek water itself.

For further investigations concerning this see next section.

ii. The other large contribution to the internal resistance is the poor connection between the membrane and the metal screen. Which is around $560 \mathrm{ohm}$, the difference between the resistance from figure $3\left(930 \mathrm{ohm} @ \mathrm{~T}=28^{\circ} \mathrm{C}\right)$ and figure 4A (370ohm @ $\mathrm{T}=28^{\circ} \mathrm{C}$ ) because the measuring setup is the same with the exception of the membrane.

iii. The mesh inside helps to decrease the internal resistance as one can see from the comparison of the results from figure $4 \mathrm{D}$ with $4 \mathrm{~A}$, because the only difference between these setups is the mesh. 


\section{Dissolved ions and their influence for the resistance}

For the following experiment, potassium chloride $(\mathrm{KCl})$ and ammonium chloride $(\mathrm{NH} 4 \mathrm{Cl})$ were added to the creek water in order to increase it's ionic conductivity. The internal resistance was measured with a conductivity bridge at $1 \mathrm{kHz}$. During this experiment the temperature was kept constant to $26^{\circ} \mathrm{C}$.

Internal Resistance vs. added ions to the creek water

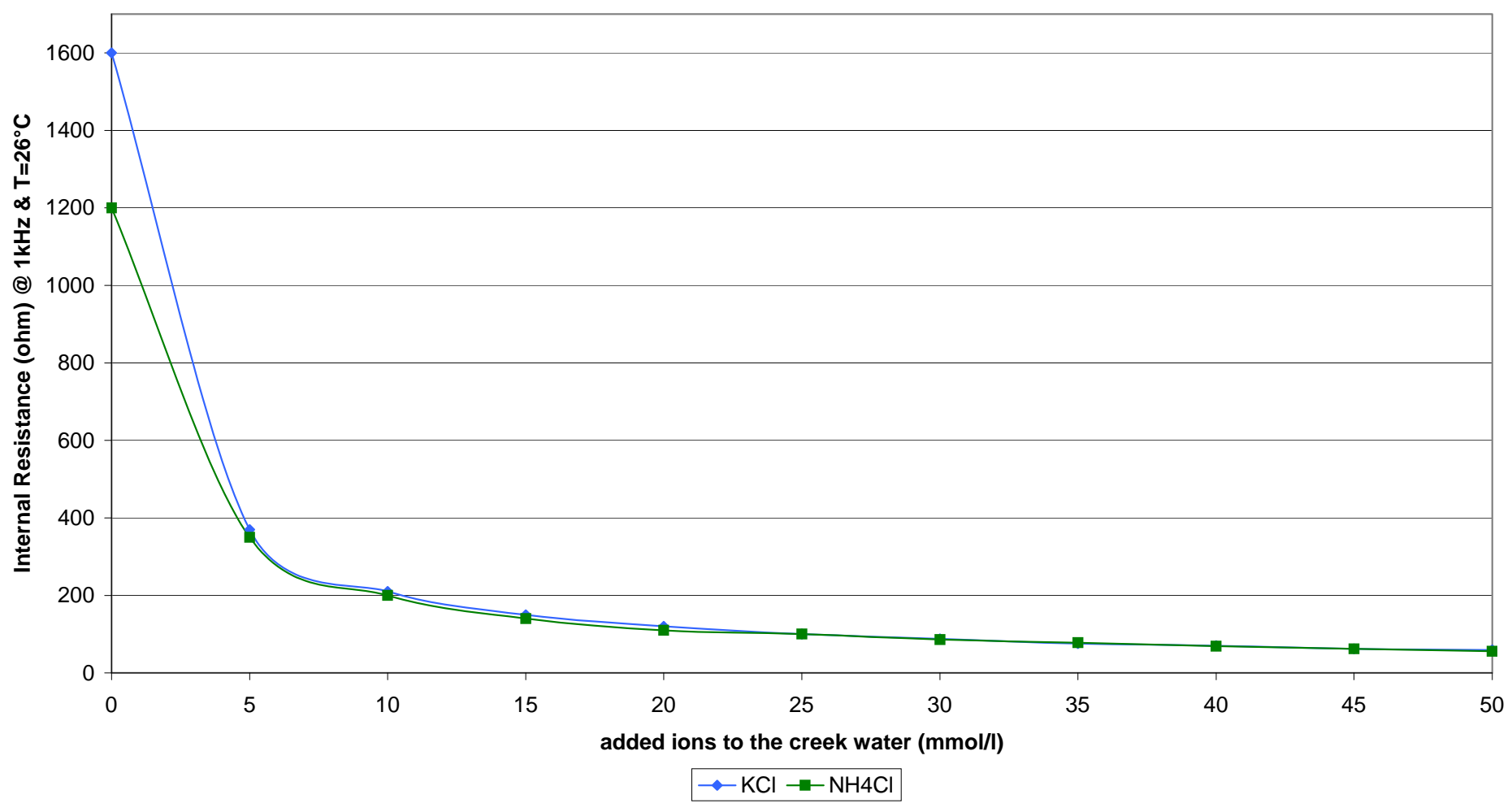

Results and conclusion for this investigation:

i. The addition of ions (K+,Cl-) dramatically improves the cell resistance and thus also the cell performance.

III.) Second run of the reactor

The microbial reactor was run under following conditions:

- $1 \mathrm{~g} / \mathrm{L}$ sugar $\left(\mathrm{C}_{12} \mathrm{H}_{22} \mathrm{O}_{11}\right)$

- Anode and cathode were connected with a $1 \mathrm{k} \Omega$ resistor and the voltage was measured over it

- Pump was turned on (Level 2) and the heater was turned on to $30^{\circ} \mathrm{C}$

- The experiment was started with $20 \mathrm{mmol} / \mathrm{l}$ dissolved potassium and ammonium chloride, which were further increased during running as mentioned in the chart below.

- As mentioned in the chart below the pump and heater were turned off during the weekend 
During the run the following parameter were measured:

i. $\quad$ Voltage (over a 1 kohm resistor)

ii. Internal Resistance with a conductivity bridge at $1 \mathrm{kHz}$. To measure the internal resistance the resistor was disconnected and then the conductivity bridge was connected to the cathode- and anode side.

iii. Temperature

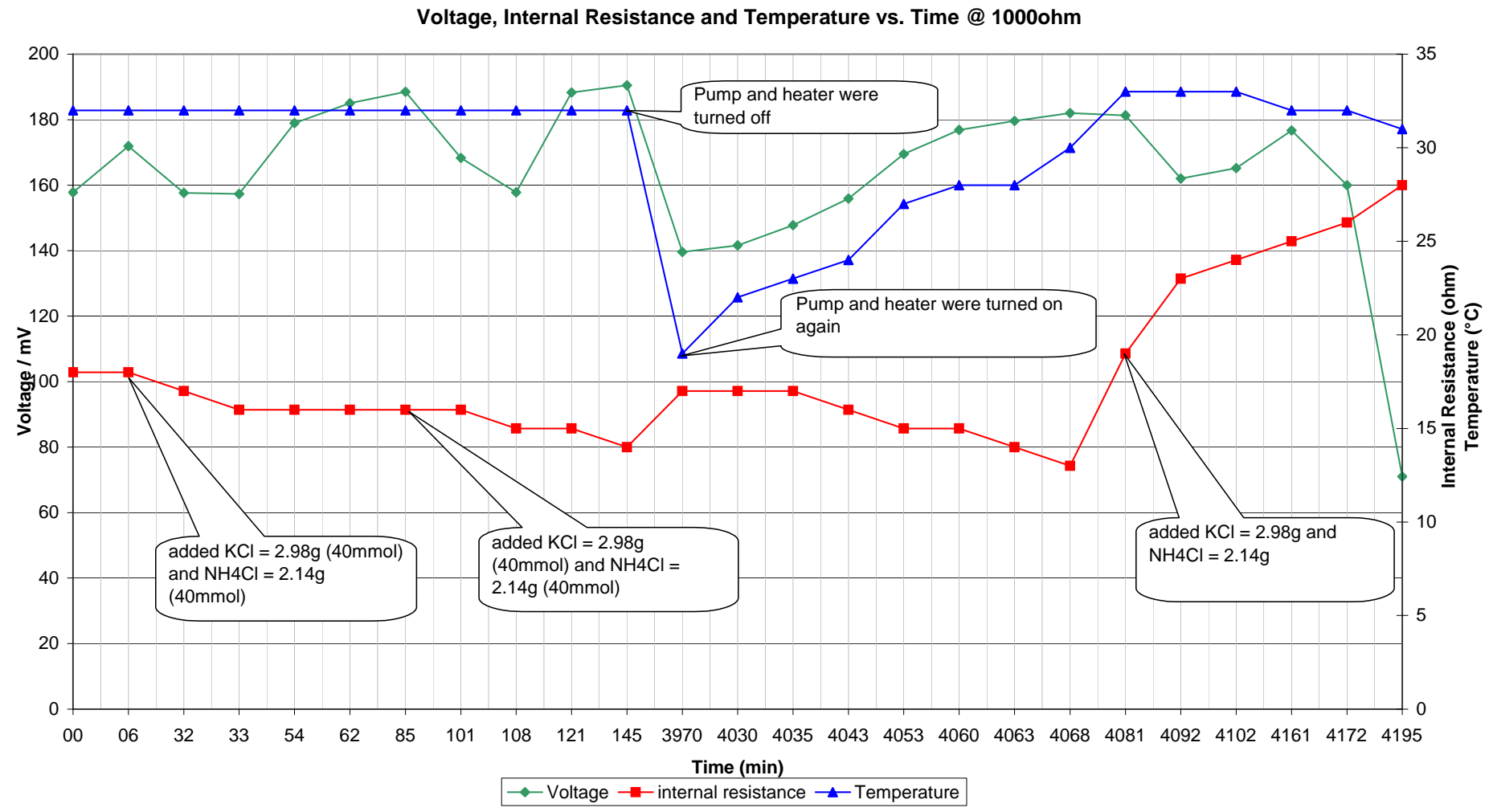

Results and conclusion for this experiment:

i. After app. 4172 min the voltage dropped dramatically and because of this the experiment was aborted. The reason for this was that the membrane was contaminated with rust. For more information about this see below.

IV.) Investigation and changes because of the Fouled membrane

Test of iron $\mathrm{Fe} 3+$ showed that there was a significant amount of Fe3+ inside the creek water after app. 4200 min running the MFC. Furthermore the screws which were used to sandwich the membrane were also corroded.

Below: Picture of the fouled membrane. 


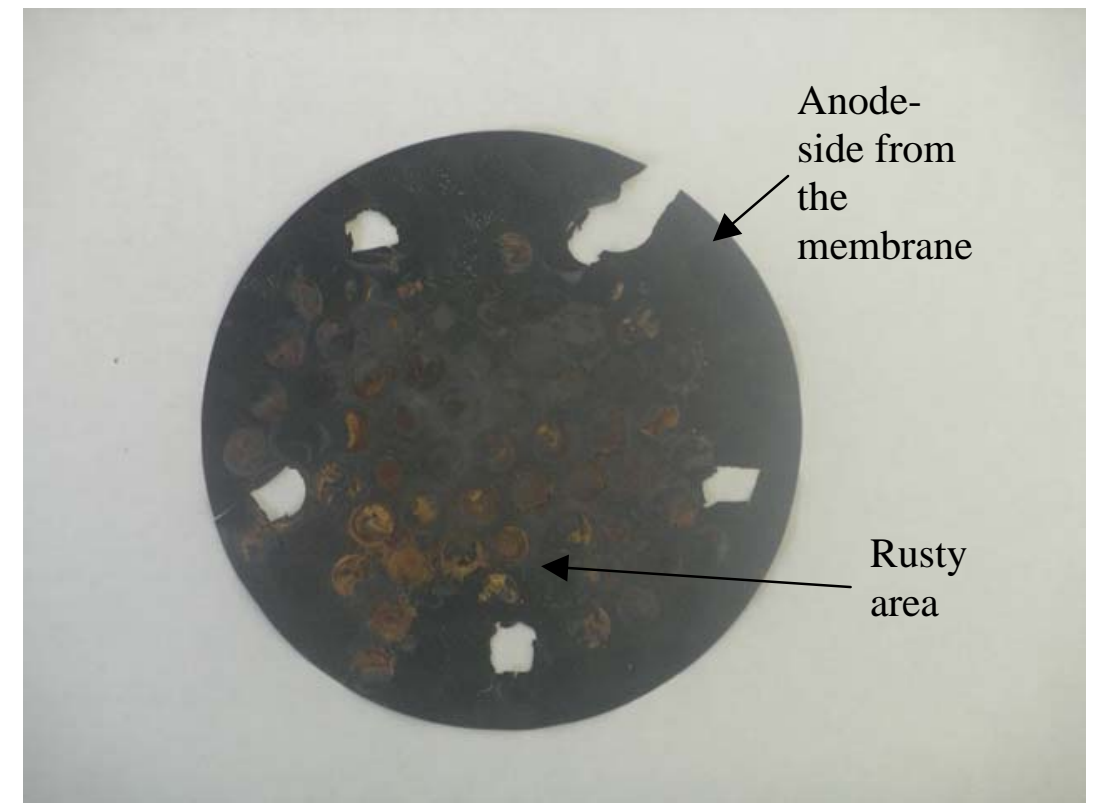

The picture shows the anode-side from the membrane.

\section{Results and conclusion:}

i. It's not possible to run the MFC with only creek water inside because the concentration of Fe3+ ions is too high. For the next run of the MFC we used only 500 $\mathrm{ml}$ creek water and filled the rest of the tank with DI water.

ii. Another reason for the rust on the membrane could be also the use of metal screws. Therefore the used screws were replaced with plastic screws, which can be seen in the picture below.

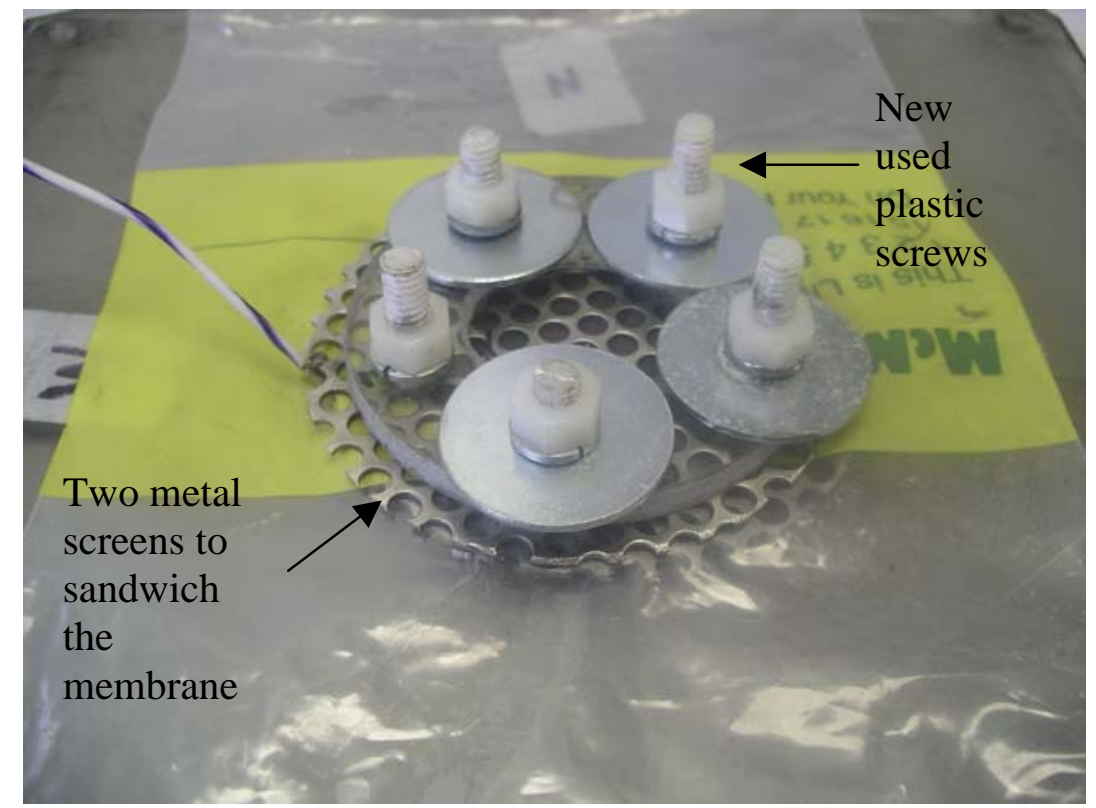


V) Fourth run of the MFC (500ml creek water, stainless steel screws, dissolved $\mathrm{KCl}$ and $\mathrm{NH} 4 \mathrm{Cl}$ )

The reactor was run under the following conditions:

- $1 \mathrm{~g} / \mathrm{L}$ sugar $\left(\mathrm{C}_{12} \mathrm{H}_{22} \mathrm{O}_{11}\right)$

- $500 \mathrm{ml}$ creek water was used and the rest of the tank was filled with DI water

- Anode and cathode were connected with a $1 \mathrm{k} \Omega$ resistor and the voltage was measured over it

- Pump was turned on and set to level 2.

- Heater was turned on and set to $33^{\circ} \mathrm{C}$ at the beginning. The temperature was changed in the range from $33^{\circ} \mathrm{C}$ till $42^{\circ} \mathrm{C}$ to determine the effect on the cell voltage.

During the run the following parameter were measured:

i. $\quad$ Voltage (over a 1 kohm resistor)

ii. Internal Resistance with a conductivity bridge at $1 \mathrm{kHz}$. To measure the internal resistance the resistor was disconnected and then the conductivity bridge was connected to the cathode- and anode side.

iii. Temperature

Voltage, Internal Resistance and Temperature vs. Time @ 1000ohm

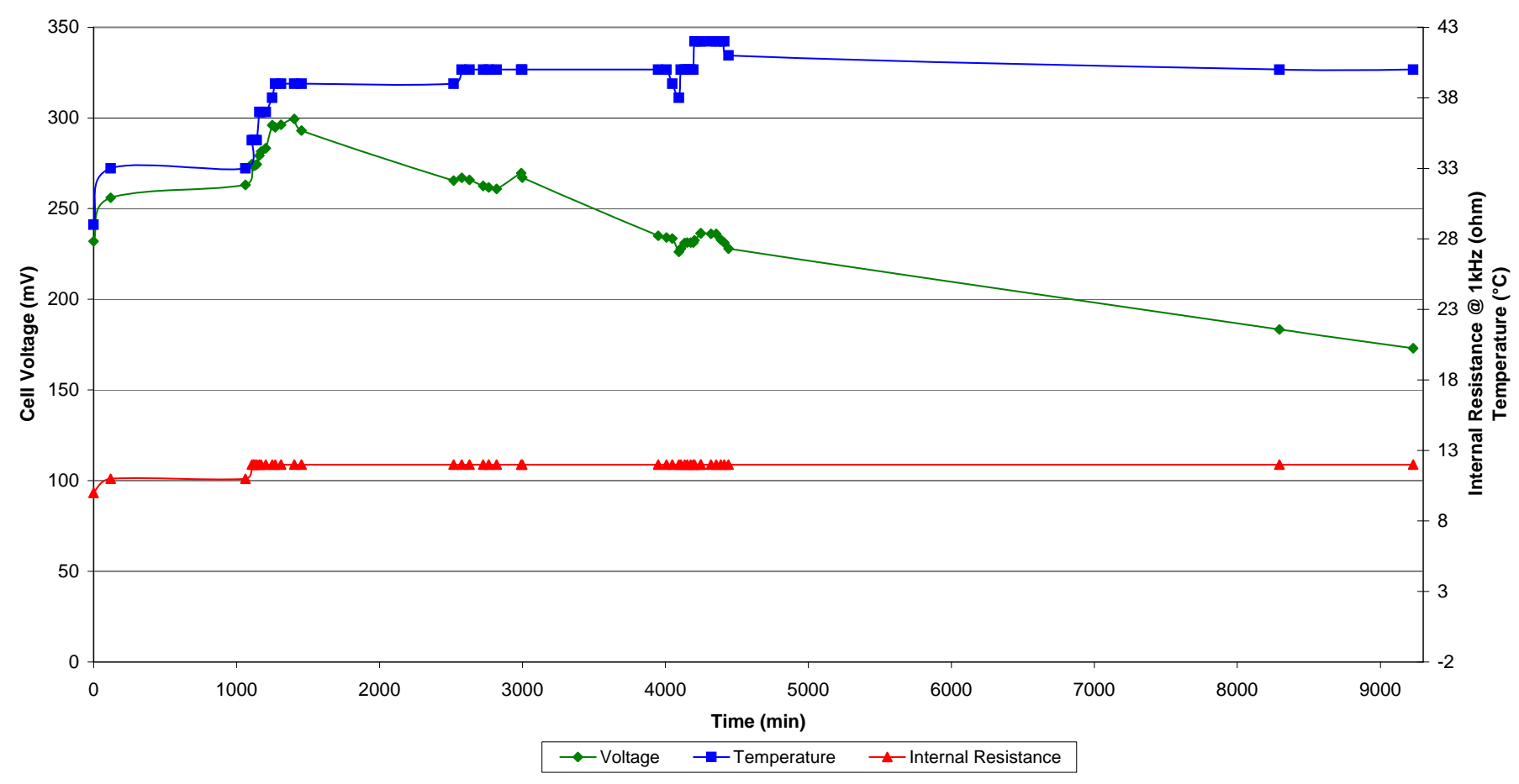


All the curves inside this chapter were made with the data from the fourth run (see above). The first chart shows a summary of all polarization curves which has been performed. The other charts show each polarization curve separately.

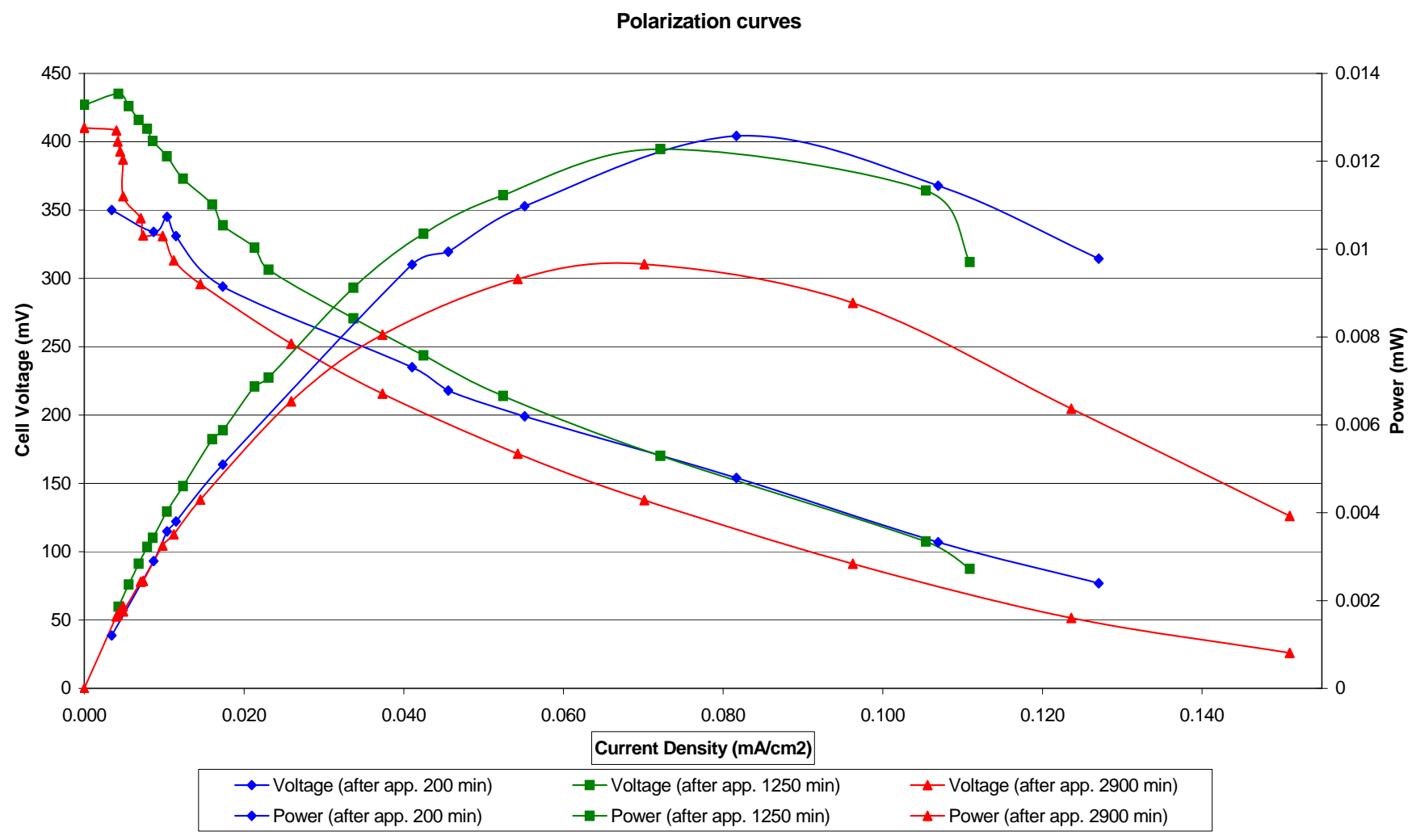

\section{Discussion and Conclusion}

We have demonstrated that the MFC can be used to generate electricity using ordinary components of construction and regular creek water. We have further demonstrated that generation of hydrogen can also be achieved at a very good efficiency relative to the electricity consumption. Furthermore the scale up of these results is quite difficult and not always as expected. We have also shown that drastic improvements in output level can be achieved in this laboratory scale reactors, however at a considerable expense of capital equipment and operating costs. For example membrane fouling can be avoided by the use of DeIonized water and stainless steel materials of construction; water conductivity can be adjusted by adding salts. These facts can dramatically influence the economics of using the MFC to offset wastewater treatment costs which by definition must be simple and robust. After implementing these cell modifications we improved our power output from 0.4 microWatts to 126 microWatts; a 300 fold increase, and when represented on a power output per sq meter of area are 122 milliWatts/sq meter of membrane. Furthermore we found that 
the microbial cells are sensitive to temperature and light and other factors that can cause the microbial activity to collapse.

Recent literature reports of optimized microbial fuel cells demonstrate 1000 milliWatts / sq meter on much smaller lab scale tests[1]. The idea of using this to generate electricity or hydrogen in my opinion still needs several orders of magnitude improvement in output power density. For example a typical municipal waste water treatment plant has an electric demand of $\$ 300,000$ / month or $3000 \mathrm{MW}-\mathrm{Hrs}$. This would require an area of 1.5 sq miles of electrode area operating at 1000 milliWatt/sq meter, clearly a ridiculously large area. In the hydrogen production mode, the consumption of electricity would still be required to perform the waste-water clean-up, and the byproduct produce hydrogen, could be collected to offset the electric costs effectively, however the problem of the enormous electrode area still needs to be overcome in order for either of the approaches to become cost effective.

[1] Logan, B.E., S. Cheng, V. Watson, and G. Estadt. 2007. Graphite fiber brush anodes for increased power production in air-cathode microbial fuel cells. Environ. Sci. Technol., 41(9):3341-3346. 